\title{
Automatic Gate Prototype Based on Microcontroller of Atmel ATMega16
}

\author{
Anna Nur Nazilah Chamim*1, Raja Erwanto ${ }^{2}$, Agus Jamal ${ }^{3}$ \\ ${ }^{1,3}$ Department of Electrical Engineering, Universitas Muhammadiyah Yogyakarta \\ J1 Lingkar Selatan Tamantirto Kasihan Bantul, (0274)387656 \\ *Corresponding author, e-mail: anna_nnc@yahoo.co.id; anna_nnc@umy.ac.id
}

\begin{abstract}
Aside from being a place of lectures, UMY also has several business units such as building rental, bus rental, autocare, and drinking water production. From the activities of UMY's business unit caused the number of outside vehicles entering UMY. The public vehicle does not have RFID as well as the UMY's internal civitas. Currently still using manpower to provide parking cards and open the door. In this study, a prototype of an automated parking system can provide a parking card and open the entrance. This prototype uses a switch as a sensor, a microcontroller as a controller, $L C D$ as a guide display for the model of vehicle that will enter, and motor servo DC as the driver of parking doors. The entire circuit is able to form a prototype automatic parking door at UMY. Copyright (C) 2017 Universitas Muhammadiyah Yogyakarta- All rights reserved.
\end{abstract}

Keywords : automatic door, parking card, public vehicle, microcontroller

\section{Introduction}

The parking system is very important for the vehicle while parking. Usually to ensure the safety of vehicles while being parked, vehicle owners are given a parking card. UMY, besides as a place of college, also has several buildings that are rented for public events. Public vehicles entering UMY do not yet have RFID cards as well as academics and internal residents of UMY. To replace the RFID card, public vehicles need to get a parking card which is currently still using the manual way by the help of humans to provide a parking card and open the entrance. This research intends to design prototype automatic parking door which is expected to be realized in order to be installed at main entrance of UMY. This prototype uses a switch as a sensor, a microcontroller as a controller, LCD as a guide sentence display for the model of vehicle that will enter, and motor servo DC as the driver of parking doors. The entire circuit is able to form a prototype automatic parking door at UMY.

\section{Literature Review}

\subsection{Microcontroller}

Microcontrollers are single chip computers that have the ability to be programmed and used for control-oriented tasks. AVR is a series of Atmel 8bit CMOS microcontrollers, based on RISC architecture (Reduced Instruction Set Computer). Almost all instructions are executed in one clock cycle. AVR has 32 general-purpose registers, flexible timer / counter with compare mode, internal and external interrupt, UART serial, programmable Watchdog Timer, and power saving mode, ADC and internal PWM.

\subsection{Language}

The broad $\mathrm{C}$ language is used for programming different types of devices, including microcontrollers. This language is already a high level language, which allows programmers to pour the algorithm.

\subsection{LCD (Liquid Cristal Display)}

LCD (Liquid Cristal Display) is one component of electronics that serves as a display of data, either 
characters, letters or graphics. In the market LCD display is available in the form of a module that is LCD display along with its supporting circuit including ROM etc. LCD has data pins, power supply controls, and display contrast controls.

\subsection{Relay}

A relay is an electronic switch that can open or close a circuit by using controls from another electronic circuit. A relay is composed of coils, springs, switches (connected to springs) and 2 electronic contacts (normally close and normally open).

\subsection{Transistor}

From the composition of semiconductor materials used, transistors can be divided into two types: PNP type transistor and NPN type transistor. In principle, the transistor is equal to two diodes arranged in reverse.

\subsection{Servo Motor}

The servo motor is a motor with a closed feedback system in which the position of the motor will be informed back to the control circuit inside the servo motor. This motor consists of a DC motor, a series of gears, a potentiometer and a control circuit. Potentiometer serves to determine the boundary angle of rotation servo. While the angle of the servo motor axis is adjusted based on the width of the pulse sent through the signal foot of the motor cable.

\section{Research Methodology}

In this research there are several steps work done to achieve the desired end result according to the flow diagram as follows.

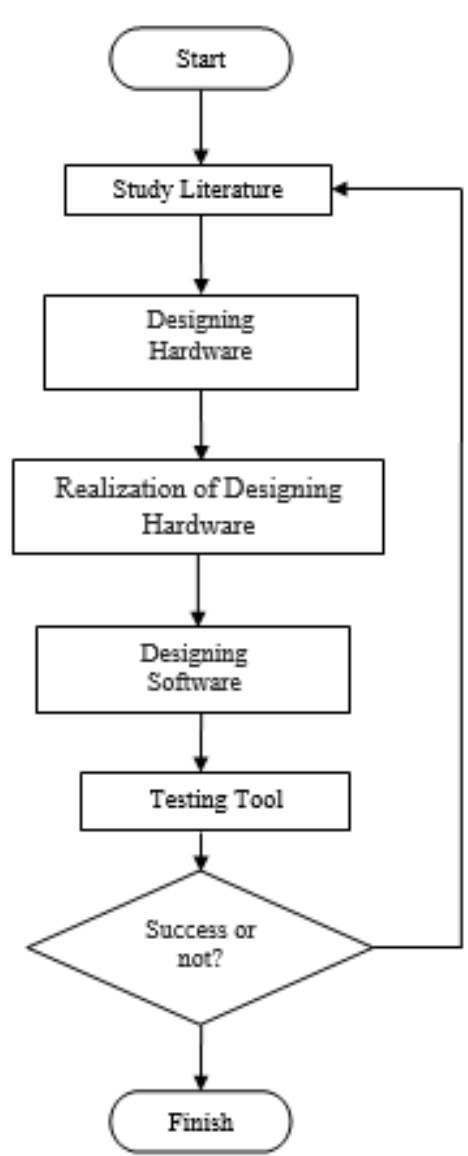

Fig.1 Flow Chart of Research

\section{Literature Review}

In this literature review was conducted to search information about everything related to the characteristics of microcontroller, work system tools, programming and its application, and the characteristics of each component.

\section{Designing Hardware}

The overall design of the tool is as follows.

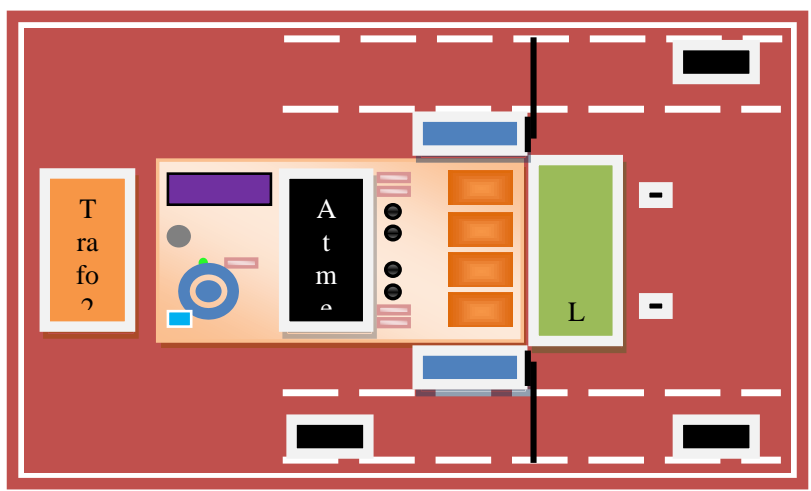

Fig.2 The Overall Design of the Tool

On the PCB placed microcontroller, relay, power supply circuit, and other supporting components. Relays are used as switches to regulate 
DC motors. The on-off switch is used to disable the prototype. While the button switch is used to reset the program on the microcontroller. Then PORTC on the microcontroller connected with the LCD as a display of words to help the driver who will enter the parking door.

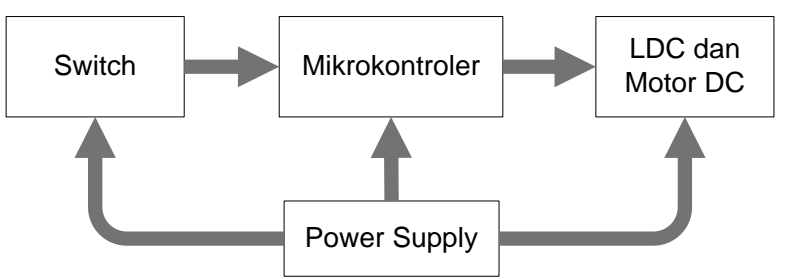

Fig.3 Block Diagram of the Tool

3. Realization of Designing Hardware

\subsection{Design of Power Supply}

Power supply is used to convert AC voltage into $5 \mathrm{~V}$ DC voltage. $5 \mathrm{~V}$ DC voltage from the power supply is used to power the circuit. The circuit of the power supply is shown in the following figure.

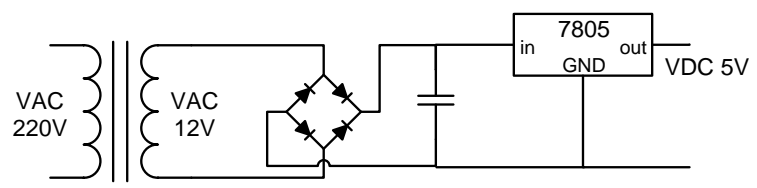

Fig.4 Power Supply Circuit

\subsection{I/O Circuit on Microcontroller}

In this prototype pin $\mathrm{A}$ on microcontroller is used as input. The A0-A4 pin is each connected to a $5 \mathrm{~V}$ voltage-mounted switch, while the A5-A7 pin is switched. Pin B0 and pin B1 are used as outputs to set the exit DC motor. Pin D0 and pin D1 are used as outputs to adjust the DC motor entrances. The $\mathrm{C} 0-\mathrm{C} 7$ pin is used as an output to control the $2 \times 16$ LCD. While the other pins each associated with VCC, ground, Crystal, button switch according to its characteristics.

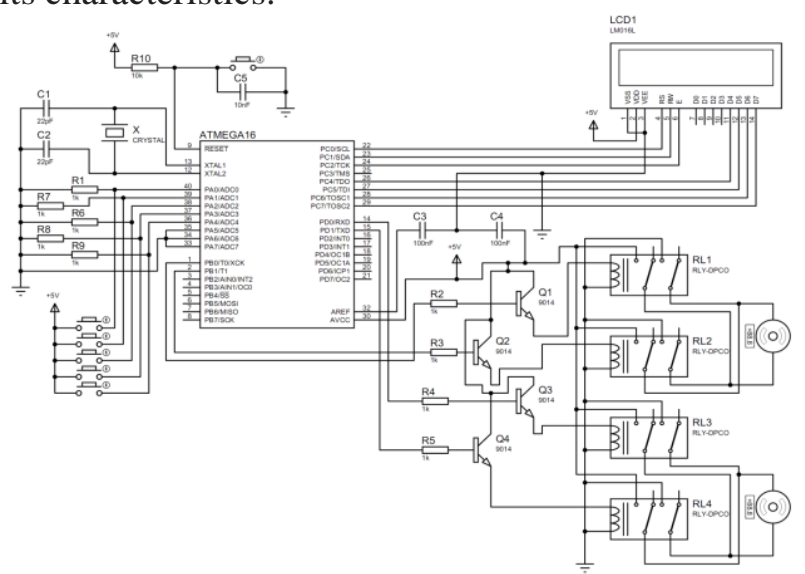

Fig.5 I/O Circuit on Microcontroller

\subsection{Main Control System}

In this research for the main controller used ATMEL ATMEGA16 Microcontroller with pin I / O counted 40 pieces.

\section{Designing Software}

The design of this software is used to write commands on Microcontroller, writing this command using Codevision AVR software with the basic principles of programming language C. Flow chart for the process of taking and processing data can be seen in the Fig.6.

The microcontroller reads the input voltage values for each pin A (A0-A7). Pin A0 serves to determine whether there is a vehicle that will enter the parking door. Pin A1 serves to find out if the user of the vehicle has taken the parking card. Pin A2 serves to find out whether the vehicle has entered the parking door. A3 Pin serves to determine whether the user of the vehicle has provided a valid parking card. A4 pin serves to determine if the vehicle has come out of the parking door.

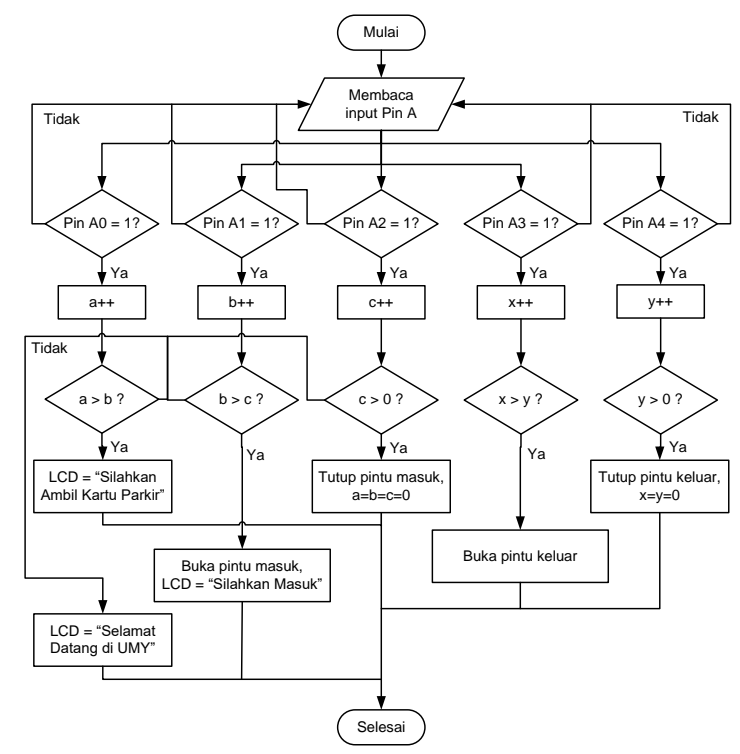

Fig.6 Flowchart of Microcontroller System

Then the conditions will be processed by the microcontroller to control the display on the LCD and DC motors driving the parking doors. In the initial conditions, LCD display the phrase "Welcome to UMY". When pin A0 is on, the LCD displays the phrase "Please Take the Parking Card". When pin A1 is on, DC motor opens the entrance and LCD displays the phrase "Please Login". When pin A2 is on, DC motor closes the entrance. When the A3 pin is on, the DC motor opens the exit. 
When the A4 pin is on, the DC motor closes the exit.

\section{Testing Tool}

Testing of design result and realization of prototype of UMY parking door is done for the circuit and its program. Testing is intended to find out which tool is made successful or not and whether according to the desired specifications or not.

\section{Results and Discussion}

\subsection{The working principle of the tool}

This prototype is designed to be able to control the entrance and exit parking and control the writing on the LCD display. The parking and writing doors on the LCD will be controlled automatically on stand-by conditions, there is a vehicle model going in, and there is a vehicle model that will exit the parking door.

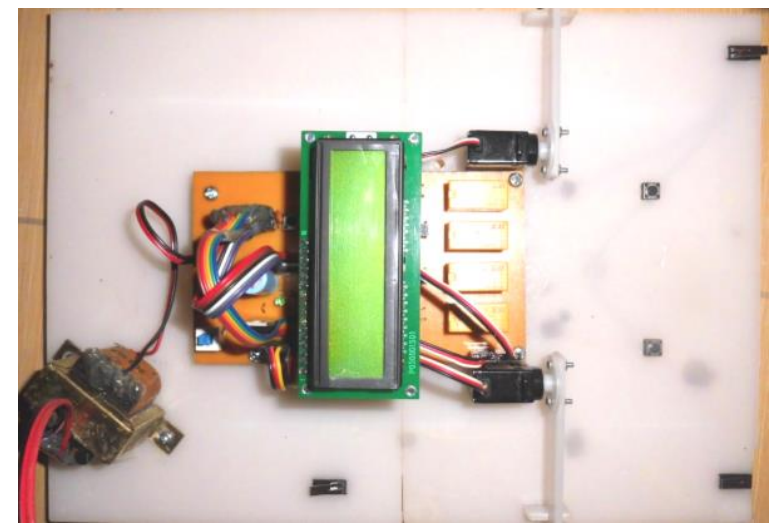

Fig.7 Prototype automatic parking door

\subsection{Programming Language}

Programs contained in Microcontroller made based on $\mathrm{C}$ programming language. Programming is done by using software CodeVision AVR. After programming, the program is integrated in microcontroller by using downloader circuit. Programs that are integrated into the Microcontroller are as follows.

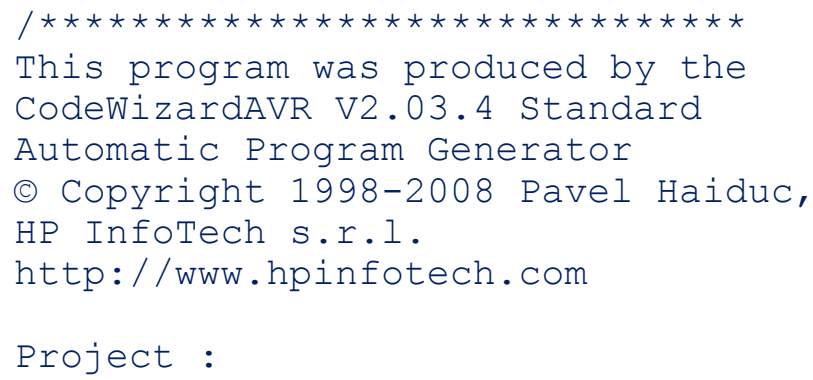

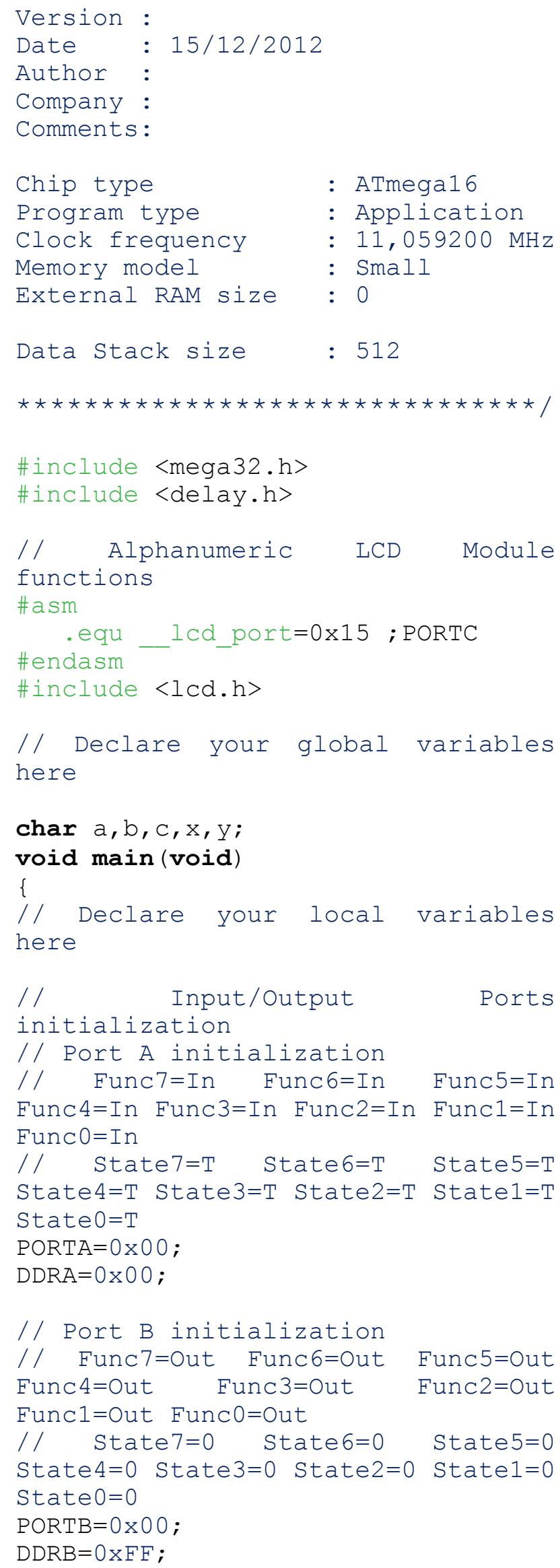


// Port C initialization

/ / Func7=Out Func6=out Func $4=$ Out $\quad$ Func $3=$ Out

Func $5=$ Out

Funcl=Out Func $0=$ Out

/ / $\quad$ State $7=0 \quad$ State $6=0 \quad$ State $5=0$

State $4=0$ state $3=0$ state $2=0 \quad$ state $1=0$

State $0=0$

$\mathrm{PORTC}=0 \times 00$;

$\mathrm{DDRC}=0 \times \mathrm{FF}$;

// Port D initialization

/ / Func7=Out Func6=out Func $4=$ Out $\quad$ Func $3=$ Out

Func $5=$ out Func1=Out Func $0=$ Out

/ / State $7=0 \quad$ State $6=0 \quad$ State $5=0$ State $4=0$ state $3=0 \quad$ state $2=0 \quad$ state $1=0$ State $0=0$

$\mathrm{PORTD}=0 \times 00$;

$\mathrm{DDRD}=0 \times \mathrm{FF}$;

// Analog Comparator initialization

// Analog Comparator: Off

// Analog Comparator Input Capture

by Timer/Counter 1: Off

$\mathrm{ACSR}=0 \times 80$;

$\mathrm{SFIOR}=0 \times 00$;

// LCD module initialization

$\mathrm{a}=\mathrm{b}=\mathrm{C}=\mathrm{x}=\mathrm{y}=0$;

lcd_init (16);

while (1)

\{

// Place your code here

/ / awal

$\mathrm{PORTD}=0 \times 00$;

lcd $\operatorname{gotoxy}(1,0)$;

lcd putsf ("Selamat Datang") ;

lcd $\operatorname{gotoxy}(5,1)$;

lcd-putsf ("di UMY") ;

// logika PINA

if $(\mathrm{PINA}==0 \times 01)$

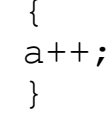

\{

$\mathrm{a}++$;

\}

if $(\mathrm{PINA}==0 \times 02)$

\{

$\mathrm{b}++$;

\}

if $(\mathrm{PINA}==0 \times 04)$

\{

$\mathrm{C}++$;

\}

if $(\mathrm{PINA}==0 \times 08)$

\{
$\mathrm{x}++$; if $(\mathrm{PINA}==0 \times 10)$

\{

$\mathrm{y}++$;

\}

//kombinasi $\quad \mathrm{PINA}=0 \times 01$ dan $\mathrm{PINA}=0 \times 08$

if $(\mathrm{PINA}==0 \times 09)$

\{

$\mathrm{a}++$;

$\mathrm{x}++$;

\}

//kombinasi PINA $=0 \times 01$ dan

$\mathrm{PINA}=0 \times 10$

if $(\mathrm{PINA}==0 \times 11)$

\{

a++ ;

$\mathrm{y}++$;

\}

//kombinasi PINA $=0 \times 02$ dan $\mathrm{PINA}=0 \times 08$

if $(\mathrm{PINA}==0 \times \mathrm{xa})$

\{

$\mathrm{b}++$;

$\mathrm{x}++$;

\}

//kombinasi PINA $=0 \times 02$ dan $\mathrm{PINA}=0 \times 10$

if $(\mathrm{PINA}==0 \times 12)$

\{

$\mathrm{b}++$;

$\mathrm{y}++$;

\}

//kombinasi $\quad P I N A=0 \times 04$ dan $\mathrm{PINA}=0 \times 08$

if $(\mathrm{PINA}==0 \times \mathrm{C})$

\{

$\mathrm{C}++$;

$\mathrm{x}++$;

\}

//kombinasi PINA $=0 \times 04$ dan $\mathrm{PINA}=0 \times 10$

if $(\mathrm{PINA}==0 \times 14)$

\{

$\mathrm{C}++$;

$\mathrm{y}++$;

\}

/ / pintu masuk

if $(a>b)$

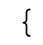

while $((\mathrm{PINA} !=0 \times 02) \quad \& \&$

$(\mathrm{PINA} !=0 \times 0 \mathrm{a}) \quad \& \& \quad(\mathrm{PINA} !=0 \times 12))$

lcd $\operatorname{gotoxy}(1,0)$;

lcd putsf("Silahkan

Ambil") ;

lcd_gotoxy $(2,1)$; 


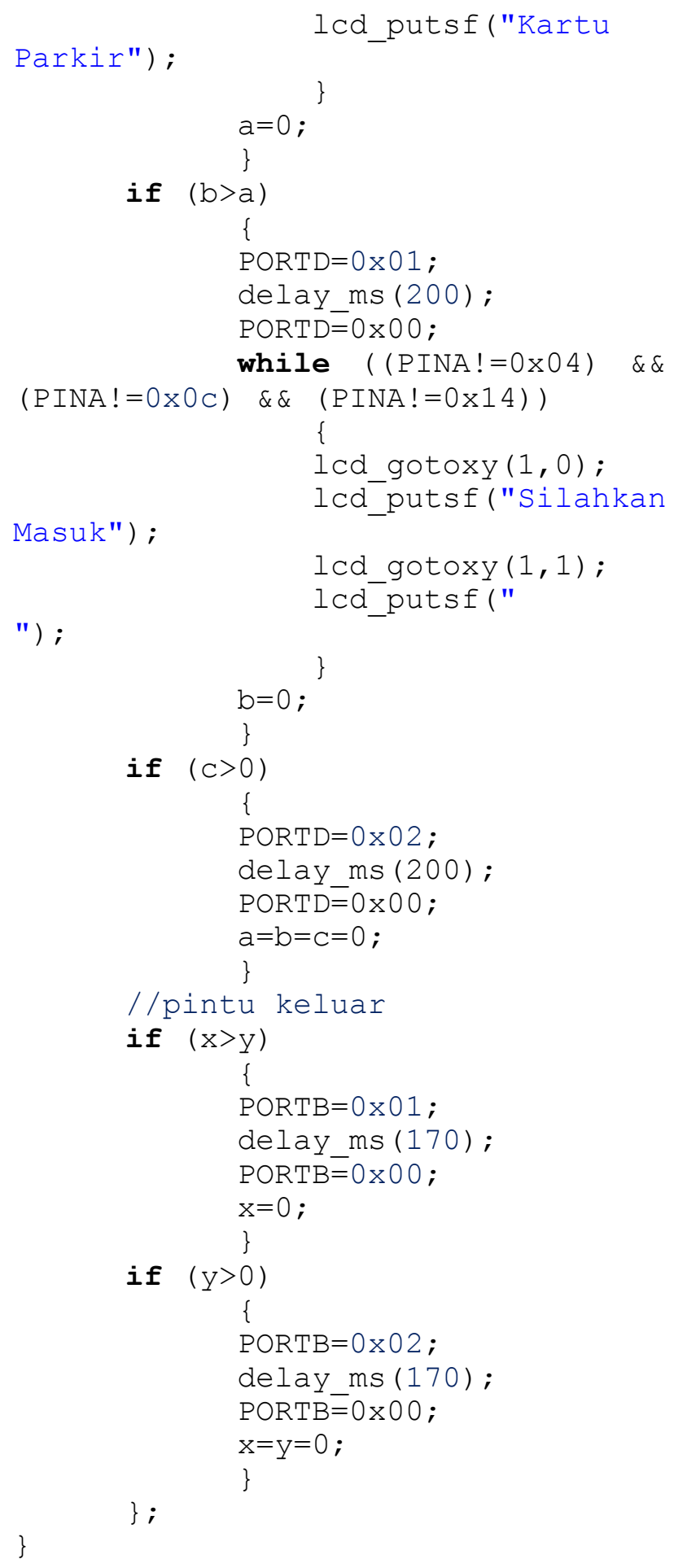

In the above program, pin $\mathrm{A}$ is used as input while pin $\mathrm{B}, \mathrm{C}$, and $\mathrm{D}$ are used as output. For LCD, the pin that is used to control it is pin C. Pin D is used to control the DC motor for parking entrance. While pin B is used to control the DC motor for the parking exit.

In the above program there are 5 pieces of variables are a, b, c, x, and y. Variable is affected by input pin A0. The variable $b$ is affected by input pin $\mathrm{A} 1$. The variable $\mathrm{c}$ is affected by input pin A2. Variable $\mathrm{x}$ is affected by input pin A3. While variable y is influenced by input pin A4.

Each variable represents certain conditions. In the initial condition pin A is entirely off, the LCD displays the phrase "Welcome to UMY". When pin A0 is active which means a> 0 , the LCD displays the phrase "Please Take Parking Card" until the A1 pin is on. When the active $A 1$ pin signifies $b>0$, the D0 pin will actively control the DC motor to open the parking entrance and the LCD displays the phrase "Please Enter" until the A2 pin is active. When pin $\mathrm{A} 2$ is on, then $\mathrm{c}>0$ so the $\mathrm{D} 1$ pin will control the DC motor to close the parking entrance and return to the starting position $\mathrm{a}=\mathrm{b}=\mathrm{c}=0$. When the $\mathrm{A} 3$ pin is on, then $\mathrm{x}>0$ so that pin $\mathrm{B} 0$ will actively control the DC motor to open the parking exit. When the A4 pin is active, then $\mathrm{y}>0$ so the $\mathrm{B} 1$ pin will actively control the DC motor to close the parking exit

\subsection{Testing}

System testing is performed to determine the performance and capabilities of the device created. Testing is done on each subsystem of the device so that it can be analyzed and concluded whether the device has been in accordance with the expected.

\subsubsection{Hardware Testing}

This test is performed in several parts, namely transistor testing, relay testing, and switches. The transistor test is performed to find out whether the transistor can connect and disconnect the voltage source for the relay. Relay test is done to find out whether the relay used can enable and disable DC motor. While the test switch is done to know whether the switch to connect or decide the current in accordance with their respective functions.

There are four transistors (in green boxes) each of which functions as a switch for the relay. When the transistors are not given current, leg $\mathrm{C}$ is not connected to the leg E. While given the current, foot $\mathrm{C}$ is connected with foot $\mathrm{E}$. This indicates that the transistor can be a connector and a breaker voltage source for the relay

There are 4 pieces of relay (in blue box) each of which serves as controller of 2 pieces DC motor. When the relay is given a voltage of $5 \mathrm{~V}$, the previously attached pole contact Normally Open (NO) changes to Normally Close (NC). This causes the DC motor to move as it is connected to a $5 \mathrm{~V}$ DC voltage source. 
There is an on-off switch to enable the prototype and 5 push pushes on. When pressed, the legs of the on-off switch are connected so that the prototype is on. When pressed again, the position of the switch goes back to normal and the legs of the switch are disconnected so the prototype is off. 5 other switches when pressed the legs are connected so that the input pins of the microcontroller connected to the $5 \mathrm{~V}$ voltage. When released the input pins are $0 \mathrm{~V}$.

\subsubsection{Software Testing}

Programming on Microcontroller using CodeVision AVR software. Programs written on Microcontroller can be seen in Section 4.2. Testing of the program is done by using Proteus 7 Professional. Program display can be seen in the following figure.

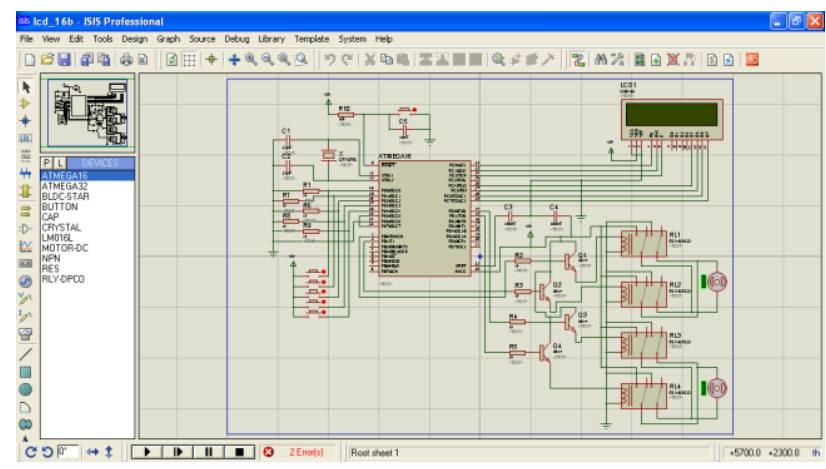

Fig.8 Proteus 7 Profesional Program View

When the play button is pressed then the program will be active and the LCD will appear as follows.

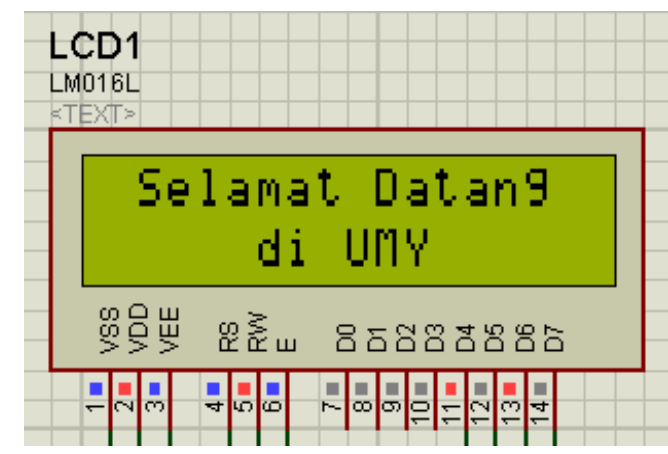

Fig.9 LCD Display on Stand-by Condition

When switch 1 is clicked indicating an input of $5 \mathrm{~V}$, the LCD will appear as follows.

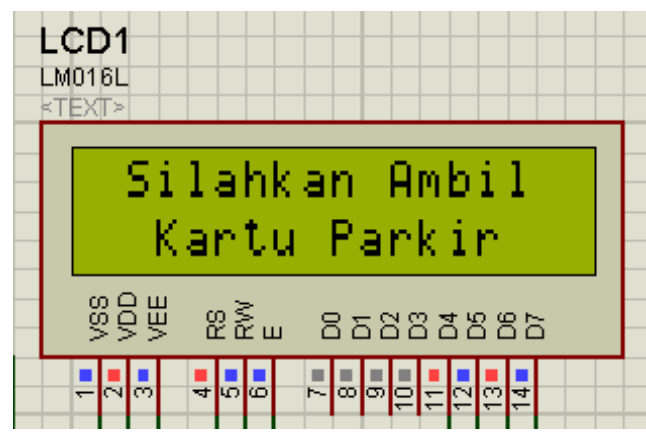

Fig.10 LCD Switch 1 Display is On

When switch 2 is clicked indicating an input of $5 \mathrm{~V}$, the LCD will appear as follows.

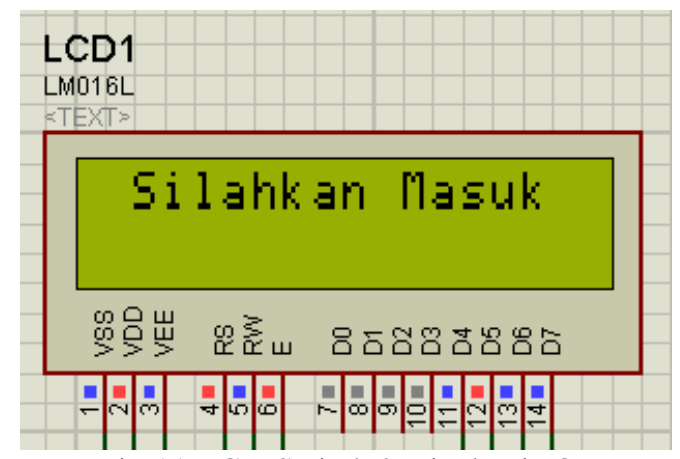

Fig.11 LCD Switch 2 Display is On

When switch 3 is clicked indicating an input of $5 \mathrm{~V}$, back to stand by condition, then LCD will appear as follows.

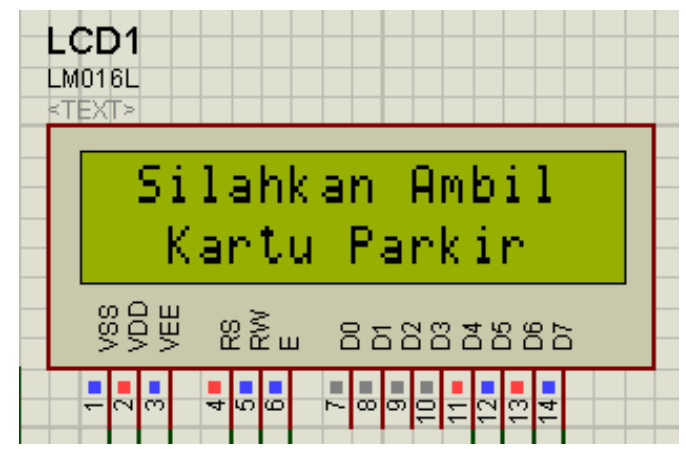

Fig.12 LCD Switch 3 Display is On

\subsubsection{Overall System Testing}

Overall system testing is intended to determine whether the system can run as desired with the test done in 6 stages.

In the initial condition when the prototype is activated pin A is entirely off, the LCD displays the phrase "Selamat Datang di UMY" as shown below. 


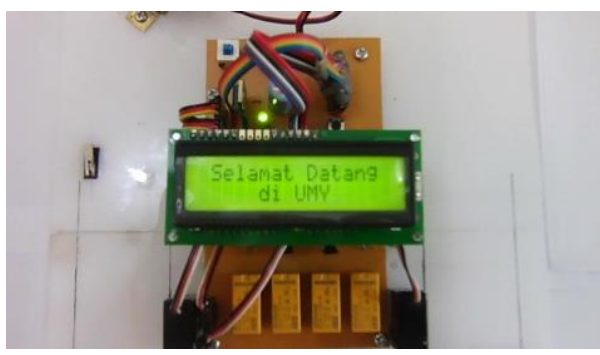

Fig.13 Stand-by Condition

In the second test, when a vehicle model will be detected entering the parking door, switch 1 will be stepped on. This causes the active A0 pin so that the LCD displays the phrase "Silahkan Ambil Kartu Parkir" as in the following figure.

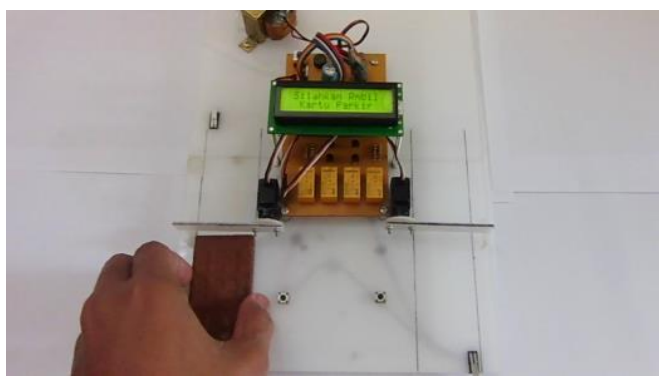

Fig.14 Condition of Vehicle Model will Enter

In the third test, after being detected that the parking card has been taken by pressing switch 2 , the A1 pin is active so the parking door will open and the LCD displays the phrase "Silahkan Masuk" as shown below.

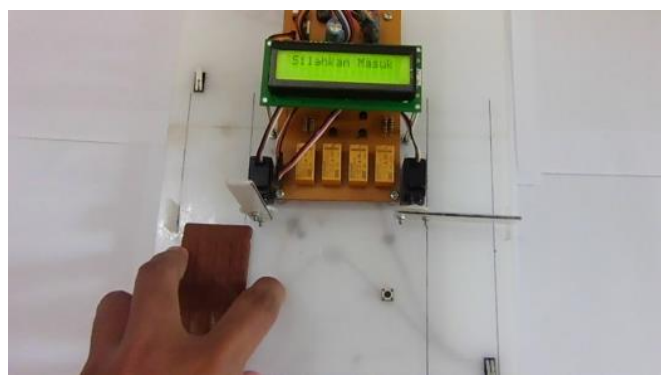

Fig.15 Parking card conditions have been taken

In the fourth test, after the vehicle model has entered the parking door, then switch 3 will be stepped on. This causes the A2 pin to activate so that the parking door will close automatically and return to the initial conditions as shown below.

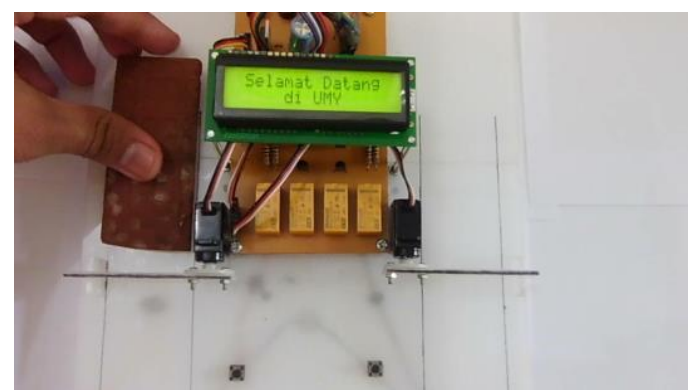

Fig.16 Condition of the vehicle model has entered

In the fifth test, when it is detected that the parking card has been returned by pressing switch 4 , then the $\mathrm{A} 3$ pin is active so the parking exit door will open as shown below.

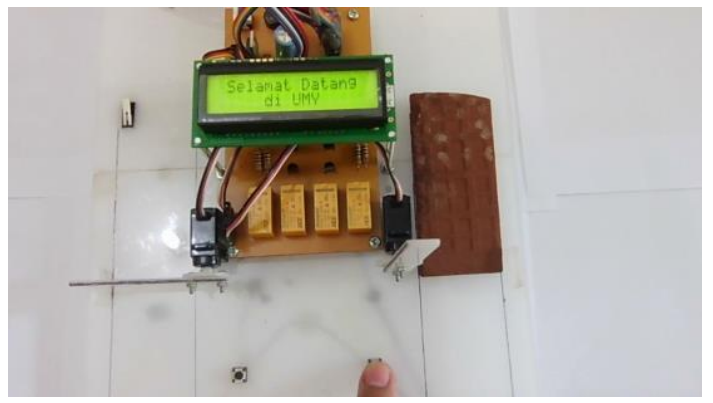

Fig.17 The Condition of the Vehicle Model will Exit and has Returned the Parking Card

In the last test, after the vehicle model came out, the A4 pin is active. This causes the A4 pin to activate so that the exit parking will be closed automatically as in the following figure.

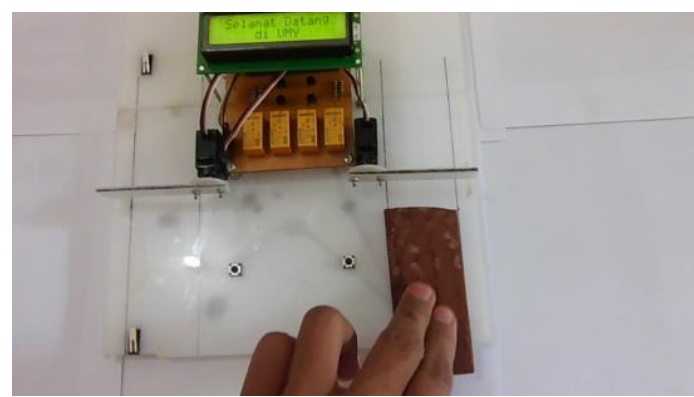

Fig.18 Condition of the Vehicle Model has been Out

\section{Conclusion}

Conclusions that can be drawn from this research, among others:

1 The push-on switch is capable of being a vehicle model sensor in various conditions.

2 LCD capable of displaying sentence instructions for the vehicle model that will enter.

3 DC servo motors are able to move the doors of the parker open and close. 
4 Microcontroller capable of being the main controller for this prototype.

5 It has been realized the prototype of automatic parking door at UMY.

\section{References}

[1] Wardhana, Lingga. 2006. Belajar Sendiri Mikrokontroller Seri ATmega8535. Andi: Yogyakarta.

[2] Winoto, Ardi. 2008. Mikrokontroller AVR Atmega8/32/16/8535 dan Pemrogramannya dengan Bahasa C pada WinAVR. Informatika: Bandung.

[3] Ammeral, L. 2000. C++ for Programmers. Third Edition. John Wiley: New York.

[4] Hartono, Jogiyanto. 2002. Konsep Dasar Pemrograman Bahasa C. Andi: Yogyakarta.

[5] Bekoy. 2012. Pemrograman LCD Karakter (2×16) Menggunakan CV AVR. $\mathrm{http} / /$ bekoy.wordpress.com.

[6] Bapuks. 2008. Dasar2 Relay, cara memasang dll.

http://forum.otomotifnet.com/otoforum/showth read.php?t=1323.

[7] Bishop, Owen. 2002. Dasar-dasar Elektronika. Erlangga: Jakarta.

[8] Huda, Akbarul. 2010. Mengenal Motor Servo. http//akbarulhuda.wordpress.com

\section{Authors' information}

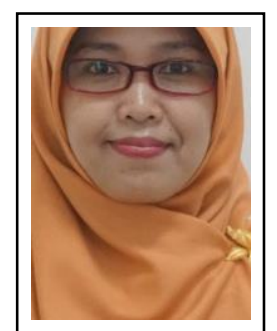

Anna Nur Nazilah Chamim received B.Sc. degree from Universitas Muhammadiyah Yogyakarta in 2001, and M.Eng. degree from Department of Electrical Engineering, Universitas Gadjah Mada, Yogyakarta, Indonesia in 2014.

Anna Nur Nazilah Chamim, M.Eng is a Lecturer in Department of Electrical Engineering, Faculty of Engineering, Universitas Muhammadiyah Yogyakarta, Indonesia. Her research interests are in image processing, telecommunication system, application of electronics, application of control system, and signal processing. 